\title{
Assessment of Environment Landscapes Restoration (ELR) in Mining Areas of Tanzania
}

\section{Pancrace Theonest Shwekelela*}

PhD Candidate and Irene Aurelia Tarimo (Supervisor at the Open University of Tanzania), Tanzania

*Corresponding Author: Pancrace Theonest Shwekelela, PhD Candidate and Irene Aurelia Tarimo (Supervisor at the Open University of Tanzania), Tanzania.
Received: August 18, 2021

Published: February 28, 2022

(C) All rights are reserved by Pancrace

Theonest Shwekelela.

\begin{abstract}
Environmental Landscape Restoration (ELR) activities in mining areas of Tanzania are crucial for ecological restoration and resources conservation. The restoration of mined land in practice is ecosystem reconstruction/the reestablishment of the capability of the land to capture and retain fundamental resources. Mining alters the natural landscape and releases large volumes of wastes that pose serious pollution to the environment, to human health and to agriculture. Mining activities and the wastes of potentially harmful elements and their effect on plants, food chains, and ultimately on human health, is not understood. This leads to climate change, global warming, and loss of biodiversity and food insecurity (SDG 13). When the extraction of mining reserve is over, the altered landscape has to be restored in order to relieve the damaging effects of mining and renovate the landscape environment (SDG 15). Despite the long times-past of mining in Tanzania, no systematic literature research paper has done review on the environmental landscape restoration after mining disturbance. Thus, the aim of this research on post-mining environmental landscape restoration in mining areas of Tanzania is inevitable. This review found that: (i) the application of Social-Ecological Systems Framework (SESF) to the HASHI ("Hifadhi Ardhi Shinyanga" - Shinyanga Soil Conservation programme, 2017) in Tanzania as a case study example on the restoration initiatives. (ii) Integrated Ecosystems assessment in Tanzania (19) Experiences in Ecosystems Management. (iii) Tanzania environmental threats and opportunities assessment [1]. (iv) Uluguru Landscape Management Framework -ULMF [2,3]. (v) Birds of Golden Pride Project area, Nzega District, central Tanzania: an evaluation of recolonization of rehabilitated areas [4]. (vi) Raising voices for blue forests: A chat with Tanzanian "mangrover" Mwita Mangora [5]. (vii) The 5th Scientific Conference on Environmental Sustainability in Tanzania: Man and Biosphere reserves [6]. Thus, from the above published papers (i) - (vii) it is evidenced that ELR is not addressed yet. It is recommended to work on this gap to restore mining ELR in Tanzania.
\end{abstract}

Keywords: Landscapes; Forests; Environment Landscapes Restoration (ELR)

\section{Introduction}

A literature review of a mature topic addresses the need for a critique of, and the potential reconceptualization of, the expanding and more diversified knowledge base of the topic as it continues to develop.

A literature review surveys scholarly articles, books and other sources relevant to a particular issue, area of research, or theory, and providing a description, summary, and critical evaluation of these works. A literature review is a description of the literature relevant to a particular field or topic being studied [7]. A literature review of this research paper addresses the need for a critique of, and the potential re-conceptualization of, the expanding and more diversified knowledge base of the $\mathrm{PhD}$ research topic of Environment Landscapes Restoration (ELR) in Mining Areas as it continues to develop at proposal stage. 
Three possible conditions of landscapes can be identified: (1) a landscape that is functioning properly and well managed, (2) a landscape that is being degraded due to unsustainable management, and (3) a landscape that is severely degraded where the net worth of restoration outcomes may not be greater than the efforts and resources required to restore it. It is necessary to note that even these categories are very subjective. This literature review paper deals with the second category/status of a landscape restoration that is being degraded due to unsustainable exploitation.

The "United Nations (UN) Decade of Ecosystem Restoration 2021 - 2030" [8] sets out the context rationale and the purpose of this study which is Restoration could remove up to 26 gigatons of greenhouse gases from the atmosphere.

Land degradation through human activities is negatively affecting the well-being of at least 3.2 billion people, costing more than $10 \%$ of the annual global gross product in loss of biodiversity and ecosystem services. The significant impacts of ecosystem degradation impair biodiversity and land productivity especially in vulnerable areas in sub-Saharan Africa, South Eastern Asia and Latin America. Ecosystem restoration can generate tangible benefits, which can increase food and water security, contribute to climate change mitigation and adaptation, and contribute to addressing associated risks such as conflicts and migration. Investing in ecosystem restoration has proven to generate benefits ten (10) times the costs of the initial investment, whereas the cost of inaction is at least three (03) times the cost of active ecosystem restoration, UNEP Publications (2019) [9].

In East Africa, restoration is being used as a tool to promote both livelihood security and forest conservation. The following three examples of projects from the region make it clear that the lessons from East Africa are pertinent to the rest of the world.

\section{Tanzania}

Local communities have improved their livelihoods by working in partnership with the Government to revitalize a traditional practice of natural resource management (USAID, 2012) [1].
Kenya

Following a severe drought, communities have re-established an extensive area of tree cover that provides food security for humans and livestock for socio-economic development (Duguma et.al., 2015) [10].

Uganda

A Dutch-funded tree planting project to compensate for emissions from European power stations has broadened its initial narrow carbon sequestration objective to include a range of social and environmental benefits for the local community [11].

Mining activities that excessively exploit natural resources at the expense of the environment not only lead to environmental and biodiversity degradation but also adversely affects the survival of species, sources of energy habitats and residents living around mining sites in the future, Fenneke Brascamp (2013) [12].

In Tanzania, Mining activities has helped the development of infrastructures, created employment opportunities, growth of towns and contributed to the establishment of various industries for socio-economic developments. However, mining is one of the human activities that cause a lot of environmental degradation during site clearing, excavation, and the completely mining processes. Mining activities have also lead to environmental damage and loss of ecological biodiversity (USAID, 2012) [1].

\section{Main body}

Tanzania has environment Laws "The environmental management Act. Na. 20 of 2004 sections 151 - 161 dealing with Environmental Restoration Easements and Conservation Orders; Environmental Impact and Audit Regulations, 2005, Mining Act. No.14 of year 2010. Also there exists establishment of Environmental departments in all Districts, Towns, Municipals and Cities from the year 2011 to date dealing with environmental issues, (NEMC, 2006) [13]. But, the reasons as why mining Environment Landscapes Restoration (ELR) is not fully addressed to the mining areas after completion of mining projects are unknown.

This Literature review paper therefore, is going to address particularly the Sustainable Development Goal (SDG15), which states, 
"protect, restore and promote sustainable use of terrestrial ecosystems, sustainably manage forests, combat desertification halt and reverse land degradation and halt biodiversity loss". In addressing this goal can then share in addressing goals Goal 6 target by 2020 , protect and restore water-related ecosystems, including mountains, forests, wetlands, rivers, aquifers and lakes. Also Goal 11 to strengthen efforts to protect and safeguard the world's cultural and natural heritage. Additionally, goal 12 to ensure sustainable consumption and production patterns by 2030 , achieve the sustainable management and efficient use of natural resources; SDG 13 (Climate Action) and SDG 14 (Life and Water). The United Nations: Transforming our World: The 2030 agenda for Sustainable development (https://www.un.org/developmentgoals.html) and then set a policy on ELR in mining areas.

Definitions and explanations of different restoration-related concepts $[14,15]$.

\section{Concept definitions}

Environment

Environment is the sum total of conditions that surrounds us at a given point of time and space. It is comprised of the interacting systems of physical, biological and cultural elements which are interlinked both individually and collectively. Environment is the sum total of conditions in which an organism has to survive or maintain its life process. It influences the growth and development of living forms.

\section{Landscape}

Is the visible feature of an area of land, its landforms, and how they integrate with natural or man-made features (https:// en.m.wikipedia.org/wiki/). A landscape includes the physical elements of geophysical defined landforms such as (ice-capped) mountains, hills, water bodies such as rivers, lakes, ponds and the sea, living elements of land cover including indigenous vegetation, human elements including different forms of land use, buildings, and structures, and transitory elements such as lighting and weather conditions. Combining both their physical origins and the cultural overlay of human presence, often created over millennia, landscapes reflect a living synthesis of people and place that is vital to local and national identity.

\section{Restoration}

To restore is to bring back the original state or to a healthy and vigorous state; the process of rebuilding the ecosystem that existed prior to disturbance; or recreating the initial structures and dynamics.

\section{Landscapes restoration}

Future Terrains defines landscape restoration as: The improvement of degraded land on a large scale that rebuilds ecological integrity and enhances people's lives (https://futureterrains.org/ what-is-landscape-restoration/). As far as the big picture is concerned, landscape restoration is defined as a planned process that aims to regain ecological integrity and enhance human well-being in deforested or degraded landscapes. Improve degraded environments by: rebuilding ecological integrity by reducing or reversing the degradation pressure; reintroducing missing or declining biodiversity. It is also connecting disconnected landscape elements; involving a mosaic of ecological habitats, communities, land uses and interest groups; ensuring that communities and habitats are enhanced by the restoration programmed; and stimulating development of a self-sustaining system. This website Future Terrains exists to tackle the challenge of degraded lands by enhancing environmental and social performance and promoting landscape restoration through good governance and sustainability.

\section{Governance}

Including controlling the land, funding, developing project goals, overcoming institutional barriers, and addressing policy and legislation; and

\section{Sustainability}

Including empowerment and capacity building, scaling in time and area, addressing alien species, and avoiding reinventing the wheel.

\section{Remediation}

To remedy is "to rectify, to make good". The process of correcting a specific problem, reversing or stopping the damage to the environment and organisms in the community.

\section{Reclamation}

To reclaim is to bring back the land to a proper state, or to provide with a suitable substitute; the physical stabilization of the terrain to bring back the land to proper state; i.e., the site will be hospitable to the original inhabitants, or those similar to the original ones; the pre- and post-disturbance land uses are nearly the same. Similar to restoration but focuses on one aspect of the ecosystems services (https://en.m.wikipedia.org/wiki/). 


\section{Rehabilitation}

To rehabilitate is an act of restoring close to a previous condition or status, not expected to bring the land back to perfection, not as healthy or in an original state as a restored land; the establishment of a stable and self-sustaining ecosystem. Rehabilitated land will prevent continued environmental deterioration and is consistent with the surrounding aesthetic values. More of managerial term, measuring costs and benefits of maintaining environmental quality and optimizing local land management capacity (https:// en.m.wikipedia.org/wiki/).

\section{Study methodology and the applicable theory}

The study used a qualitative approach, and specifically a descriptive literature survey, in information collection and analysis. Gaia Theory on nature was used to guide the study.

The theory proposes that organisms interact with their inorganic surroundings on earth to form a synergistic self-regulating, complex system that helps to maintain and continue the conditions for life on the planet. The chemist James Lovelock formulated this theory and it was co-developed by microbiologist Lynn Margulis in the 1970s. Gaia theory suggests that organisms are co-evolving with their environmental surroundings, that is, they influence their abiotic environment and that the environment in turn influence the biota by Darwinian process. In some versions of the Gaia theory, all life forms are considered as part of "one single living planetary" being called Gaia. In view of this theory, the earth is the only planet currently known to harbor life; it is inevitable to ensure that people are made aware of some environmental risks/effects from mining activities. These may lead to loss of life from the mother earth environment and hence, enable them make informed decisions as to how they ought to take care of their environment to sustain good health. Thus, Environmental Education (EE) and Landscapes Restoration programmes can help to achieve these.

Adverse effects of mining activities on the environment and human health

The adverse effects on physical, ecological, biological, social, economical and infrastructure environments of mining activities increases with increasing mined area [16-18]. The most notable impact of mining is the change in land form caused by clearing of vegetation, removal of topsoil and disposal of large amounts of mine wastes which can affect the health of people in the surrounding community. Mine wastes usually include waste rock, overburden, slag, and tailings on land surfaces, while mine wastelands are comprised of stripped areas, open-pits, loose soil piles, waste rock and overburden surfaces, sub-sided lands, tailings dams and other lands degraded by mining facilities [19-22].

\section{Physical environmental effects}

Physical effects are significant land disturbance, erosion, subsidence and instability, alteration of water courses, effects on quality, quantity or availability of surface water or underground, salination of water or land, acid drainage and heavy metal contamination, among others.

Abel and Chris (2021) [23] assessed the State-led efforts to reduce environmental impacts of Artisanal and Small Scale Mining in Tanzania: Implications to fulfillment of the SDGs. The study found out that the impacts included deforestation, mercury and cyanide emissions, water pollution, soil contamination, and lack of reclamation. It is recommended to implement the set out Policies and Laws applicable to the Environmental degradation so as to restore the health environment for sustainable development.

\section{Ecological and biological environmental effects}

Ecological and Biological environmental effects include vegetation massive clearing, loss of habitats, displacement/extinction of fauna and flora, impact on ecological processes, loss of biodiversity by effect on rare or endangered flora and fauna, potential spreading of plants/animals diseases and noxious weeds, effects of toxic or hazardous materials to mention a few. The research conducted by Chacha (2017) [24] assessed the impact of Small Scale Mining on Land Resources in Tarime District, Tanzania. It was found that artisanal and small scale mining activities contributed to land surface and soil destruction, erosion, land pollution, water pollution, outbreak of diseases, occupational diseases (silicosis, mercury poisoning), respiratory problems, deforestation, death and injuries. Land for cultivation has greatly diminished; and now there is great competition for agricultural land and for grazing of livestock. It was recommended to introduce training and education to the Artisanal and Small Scale Miners as well as the surrounding communities.

\section{Social environmental effects}

Large influx of population to mining areas has potential effects on health and welfare, safety, quality of life of individuals and communities through effects of traffics, odours, noises and dust. Dislocation/relocation of people -migration, changes of the level or nature of community resources like cultural characters, distribution of jobs and income, community identity and conflicts. 
The study conducted by Kitula (2006) [25] assessed the socioeconomic and environmental impacts of mining in Geita District, Tanzania. Recommend that the marked environmental and interrelated socio-economic improvements can be achieved within regional artisanal gold mines if the government provides technical support to local operators, with improved regulations, and illegal mining activities reduced.

\section{Economic and infrastructure environmental effects}

Large load on services and infrastructures such as roads, power supply, water supply, housing, hospitals, education and other social services as well as contamination of air, land and water sources. Mining does result in the loss of access to land and forest based resources communities depend on heavily, such as timber and nontimber forest products (NTFPs) for subsistence and incomes [26]. Loss of access to land and environmental resources can also result from dislocation. Poor compensation of dislocation victims regarding lost land [27].

Tanzania legal framework on the environment and mining activities

- $\quad$ Tanzania Mining Policy, 1997;

- The National Environmental Policy,1997;

- $\quad$ Tanzania Land Policy, 2016 R.E. 1995;

- The environmental management Act. Na. 20 of 2004;

- Environmental Impact and Audit Regulations, 2005;

- $\quad$ Mining Act. No.14 of year 2010.

- Public Health Act No. 1 of 12 March 2009

- The land Act No. 1999

- Tanzania - Explosives Act - 1963

- The Town and Country Planning Act year cap 3550

- Tanzania Forest Act, 2002 - Tanzania Forest Services Agency (TFS)

- The water supply and sanitation act, 2009

- The Tanzania food, drugs and cosmetics act, 2003.

The Policies and Acts address the major environmental problems facing Tanzania which are land degradation, lack of accessible, good quality water for urban and rural inhabitants, environmental pollution, loss of wildlife habitats and biological diversity, deterioration of aquatic systems and deforestation.

Mining areas landscapes restoration programmed

One has to tell the state of the mining site before, during and after mine closes which are important the restoration planning of the site and the preserving of mining environmental database needed for research, monitoring and evaluation, and the mining site management in Africa [2]. Three alternatives for landscapes restoration: to leave the landscapes alone-set aside areas as refuges; to restore it to a condition resembling its original state, or to transform them into 'artworks' but wonder whether such artistic restoration can really redeem the landscapes [14].

The success of the restoration in accruing economic, aesthetic, physical, biological, and biodiversity, terms depend upon the goals, resources, skills and capabilities of the project teams in charge of restoration, upon the specific local challenges of the areas, the properties of the mine spoils/wastes left near the ground surface, and management afforded to the sites.

The in depth analysis of mining data content in Tanzania include the study conducted by Lema (2016) [28] assessed the contribution of small scale mining towards environmental degradation. Field observation, insitu measurements and laboratory analysis were conducted to determine environmental consequences caused by poor adherence to standard mining practices by artisanal and small scale miners in Ashiraq Mines in Tanzania. Field observation revealed significant land and soil disturbance in the study area such as the existence of abandoned old workings. The research carried out by Japhet Ringo and Mayengo (2016) [29-32] about the effects of limestone mining on deforestation and land degradation in Usongwe Division, Mbeya Region, Tanzania revealed that 38.3 ha of forests were cleared out of the 1000 ha leased to Mbeya Cement Company Limited. Similarly, soil erosion, loss of vegetation, and air pollution were the main effects exacerbated by limestone mining. Measures to the restore ecological function in the areas surrounding limestone mining sites included steep slope levelling, afforestation, and flood control. To mitigate deforestation and land degradation; rehabilitation, reclamation, and restoration measures to the best land use for future generation were suggested to be in place.

\section{Conclusions and Recommendations}

First, all stakeholders should be involved in mining Environment Landscape Restoration (ELR). The artisanal small scale miners, Medium and large scale miners, Firms and Companies should be fully involved from the planning stage up to evaluation stage of ELR programme and finally doing ELR. Early planning can identify most environmental issues which looks at effects on physical, biological and social environments through the life of the projects on the environment. 
Second, Environmental Education (EE) programmes should include information about negative effects of mining activities on the environmental health and the benefits of ELR in Ecosystems.

Third, there is urgent need to have EE as a standalone subject in schools so that it is taught from the foundation stage up to tertiary level.

Fourth, it is recommended that Schools can start the School Environmental Education Development Strategy (SEEDS). SEEDS meant to inculcate a sense of responsibility in the young ones who are the future generations to learn to look after the fragile Mother Environment for Sustainable Development to meet the SDGs by year 2030 .

Firth, Tanzania has the Environmental Management Act. (EMA) No. 20 of 2004 with sections 151-161 dealing with Environmental Restoration Easements and Conservation Orders and Environmental departments in all Districts, Towns, Municipals and Cities from the year 2011 to date dealing with environmental issues but still ELR is not fully implemented. Why, there is a need of conducting further research on mining Environment Landscapes Restoration (ELR) for the Environmental Restoration Easements and Conservation Orders to be implemented.

\section{Bibliography}

1. USAID -Tanzania. "Tanzania environmental threats and opportunities assessment”. Bruce Byers (Team Leader), Zakiya Aloyce, Pantaleo Munishi, and Charles Rhoades. Kilombero, Morogoro (2012): 145.

2. Emmanuel Timothy Malisa. "Interplay of formal and informal grassroots institutions for land management in the Uluguru Mountains, Morogoro, Tanzania (2016).

3. Chamshama SAO., et al. "Uluguru Landscape Management Framework (ULMF)". Sokoine University of Agriculture Morogoro, Tanzania (2008).

4. Chacha Werema., et al. Birds of Golden Pride Project area, Nzega District, central Tanzania: an evaluation of recolonization of rehabilitated areas (2016).

5. Mwita Mangora. Raising voices for blue forests: A chat with Tanzanian "mangrover" (2018).

6. NEMC. The 5th Scientific Conference on Environmental Sustainability in Tanzania: Man and Biosphere reserves (2019).
7. Sally. A Synthesis Matrix as a Tool for Analyzing and Synthesizing Prior Research (2013).

8. "United Nations (UN) Decade of Ecosystem Restoration 2021 - 2030". (2021).

9. UNEP Publications. The degradation of the planet threatens food security, water supplies and the biodiversity upon which human development depends (2019).

10. Duguma LA., et al. "Landscape restoration from a social-ecological system perspective?" In Minang, P. A., van Noordwijk, M., Freeman, O. E., Mbow, C., de Leeuw, J., and Catacutan, D. (Editions.) Climate-Smart Landscapes: Multifunctionality in Practice Nairobi, Kenya: World Agroforestry Centre (ICRAF) (2015): 63-73.

11. Barrow Edmund., et al. "Forest Landscape Restoration: Building Assets for People and Nature - Experience from East Africa". IUCN, Gland, Switzerland and Cambridge, UK. (2002).

12. Fenneke Brascamp. "Landscape restoration through innovative landscape governance. A case study of coal mining in East Kalimantan, Indonesia. MSc. Forest and Nature Conservation, specialization policy". Forest and Nature Conservation Policy Group (FNP). Wageningen University (2013).

13. National Environment Management Council (NEMC), Restoration of dry land ecosystems: The case of Shinyanga Region, Tanzania (2006).

14. Kuter N. Reclamation of Degraded Landscapes due to Opencast Mining (2013).

15. Bozzano M., et al. "Genetic considerations in ecosystem restoration using native tree species". Rome: FAO and Bioversity International (2014).

16. Limpitlaw D and Woldai T. "Impact of Mining on the Environment in the South African Development Community (SADC), Southern Africa (Issues and Approaches in Mapping with test case from Kitwe mine, Zambia) Conference Paper - University of the Witwatersrand (2000).

17. Cooke JA and Johnson MS. "Ecological restoration of land with particular reference to the mining of metals and industrial minerals: A review of theory and practice (C) 2002 NRC Canada, Environ". Rev 10 (2002): 41-71. 
18. Mavis Cheelo Siambwati. "Role of Environmental Education in addressing effects of coal mining in zambia's maamba township. University of Zambia, Lusaka (2016).

19. Wong MH. Land remediation and ecological restoration of mined land (2003).

20. Li MS. "Ecological restoration of mine land with particular reference to the metalliferous mine wasteland in China: a review of research and practice". Science of the Total Environment 357 (2006): 38e53.

21. Sikaundi Gift. "Copper Mining Industry in Zambia-Environmental Challenges". Environmental Council of Zambia (2016).

22. Venkateswarlu K., et al. "Abandoned metalliferous mines: ecological impacts and potential ap-proaches for reclamation". Reviews in Environmental Science and Bio/Technology 15 (2016): $327 \mathrm{e} 354$.

23. Abel Kinyondo and Chris Huggins. "State-led efforts to reduce environmental impacts of artisanal and small-scale mining in Tanzania: Implications for fulfillment of the sustainable development goals". Journal of Environmental Science and Policy 120 (2021): 157-164.

24. Chacha Kisiri T. "Assessment of the Impact of Small Scale Mining on Land Resources in Tarime District, Tanzania. Masters thesis". The Open University of Tanzania (2017).

25. AGN Kitula. "The environmental and socio-economic impacts of mining on local livelihoods in Tanzania: A case study of Geita District". Journal of Cleaner Production 14.3-4 (2006): 405-414.

26. Mwitwa Muimba-Kankolongo German and Puntodewo. Governance and sustainability challenges in landscapes shaped by mining: Mining-forestry linkages and impacts in the Copper Belt of Zambia and the DR Congo (2012).

27. Custer and Nordband. "Poor compensation of dislocation victims regarding lost land. International Journal of Education and Research". In: Precious Moyo Shoko and Jacob Mwitwa (2015). Socio-economic impact of small scale emerald mining on local community livelihoods: the case of lufwanyama district, University of Copperbelt, Zambia 3.6 (2008).

28. Lema MWJ. "Environmental consequences related to poor adherence to standard mining practices by artisanal and small scale miners: The case of Ashiraq mines, Tanzania". American Journal of Environmental Engineering and Science 3.3 (2016): 14.
29. Ringo and Mayengo. Effects of limestone mining on deforestation and land degradation in Usongwe Division, Mbeya Region, Tanzania (2016).

30. Edmund Barrow., et al. "Forest Landscape Restoration is a process that aims to regain ecological integrity and enhance human well-being in deforested or degraded forest landscapes". International Union for Conservation of Nature and Natural Resources (2002).

31. Emma Sandell Festin., et al. "Progresses in restoration of postmining landscape in Africa (2019).

32. Japhet Elisante Ringo and Gabriel Mayengo. Effects of Limestone Mining on Deforestation and Land Degradation in Mbeya Region, Tanzania (2016).

\section{Assets from publication with us}

- Prompt Acknowledgement after receiving the article

- Thorough Double blinded peer review

- Rapid Publication

- Issue of Publication Certificate

- High visibility of your Published work

Website: www.actascientific.com/

Submit Article: www.actascientific.com/submission.php Email us: editor@actascientific.com

Contact us: +919182824667 